\title{
Learner Capstone Panels for Immersing Undergraduates in Mechanisms of Engineering Research
}

\section{Mr. Soheil Salehi, University of Central Florida}

Soheil Salehi received his M.Sc. degree in Computer Engineering in 2016 from Department of Electrical and Computer Engineering of the University of Central Florida, Florida (UCF), USA. He is a Graduate Research Assistant (GRA) and currently working toward the Ph.D. degree in Computer Engineering at the University of Central Florida, Orlando, Florida, USA. His research interests include: Reconfigurable and Adaptive Computer Architectures, Spintronic-Based Computing Architectures, and Low Power and Reliability-Aware VLSI circuits. He has also been a Graduate Teaching Assistant (GTA) for Department of Electrical Engineering and Computer Science of UCF from 2014 to 2018. His educational interests are innovations and laboratory-based instructions, technology-enabled learning, and feedback driven grading approaches. He is the recipient of the Award of Excellence by a GTA for the academic year of 2015-2016 at UCF.

\section{Dr. Ramtin Zand, University of Central Florida}

Ramtin Zand received B.Sc. degree in Electrical Engineering in 2010 from IKIU, Iran. He received his M.Sc. degree in Digital Electronics from Sharif University of Technology, Tehran, Iran, in 2012. He is a Ph.D. Candidate in Computer Engineering at the University of Central Florida (UCF), Orlando, FL. His research interests include Machine Learning and Neuromorphic Computing, Emerging Nanoscale Electronics including Spin-based Devices, Reconfigurable and Adaptive Computer Architectures, and Low-Power and Reliability-Aware VLSI Circuits.

\section{Dr. Ronald F. DeMara P.E., University of Central Florida}

Ronald F. DeMara is a Professor in the Department of Electrical and Computer Engineering at the University of Central Florida (UCF), where he has been a full-time faculty member since 1993. His educational research interests focus on classroom instructional technologies and the digitization of STEM assessments. He is Principal Investigator of the NSF Workshop on Digitally-Mediated Team Learning and the organizer of faculty development workshops on Assessment Digitization Innovation and also on Virtualized Active Learning. He has completed over 275 technical and educational publications, 47 funded projects as PI/Co-I, and 22 Ph.D. graduates. He serves as the founding Director of the Evaluation and Proficiency Center (EPC), is an iSTEM Fellow, and the Digital Learning Faculty Fellow at UCF. He received the UCF university-level Scholarship of Teaching and Learning Award twice, Teaching Initiative Program Award four times, Research Initiative Award twice, Excellence in Undergraduate Teaching Award, Advisor of the Year, Distinguished Research Lecturer, Marchioli Collective Impact Award, the Effective Practice Award from Online Learning Consortium, and the Joseph M. Biedenbach Outstanding Engineering Educator Award from IEEE. 


\title{
Learner Capstone Panels for Immersing Undergraduates in Mechanisms of Engineering Research
}

\author{
Soheil Salehi, Ramtin Zand, and Ronald F. DeMara \\ Department of Electrical and Computer Engineering \\ University of Central Florida \\ Orlando, FL 32816
}

\begin{abstract}
A novel and transportable approach to integrating research methods, professional conference activities, and technical current topics has been innovated at University of Central Florida (UCF), integrated within a required undergraduate Computer Engineering course, and refined across five consecutive semesters. The Learner Capstone Panel (LCP) approach extends traditional laboratory projects towards a student-driven culminating technical panelist activity offering multiple modes for student participation. The written component of LCP consists of creating of a capstone technical report using recent technologies that extend the topics and content covered in the course. The verbal component of LCP uses those student-authored reports to conduct a conference-style activity as a peer learning forum of student panelists convened during the last day of class.
\end{abstract}

LCP motivates learners to become immersed in mechanisms of creating technical reports in IEEE format that connect the content of the course to the state-of-the-art advances in the field. Students then participate in double-blind technical review processes to select panelists who will answer questions asked by other students. To facilitate technical topic debate, the panel is conducted using real-time collaboration tools and professional protocols. Thus, undergraduate students become immersed in mechanisms associated with technical research while becoming more aware of options that they could pursue during graduate studies in topics of their interest that also refresh content within the course. Students increase preparation for their future career in academia or industry, including the development of soft skills and increased confidence to articulate their technical ideas and knowledge. This approach can be further extended to all STEM fields to enhance learner engagement in research-based tasks and increase learning outcomes relating to creative and professional activities. Our results based on an IRBapproved survey indicate that $81 \%$ of the participants strongly agreed or agreed that attending the panel discussions increased their understanding of research topics related to the course materials. Furthermore, 94\% of the survey responders strongly agreed or agreed that working on a capstone report helped them better understand the process of creating a research paper, while $75 \%$ of the responders strongly agreed or agreed that the LCP method motivated them to explore beyond the course materials. Overall, the LCP approach can offer an effective mechanism to advances students' professional development via simulated participation in a professional technical conference panel environment, which is typically unattainable for undergraduate students.

\subsection{Introduction}

\subsection{Motivation for Introducing Research Mechanisms to Undergraduates}

Introducing undergraduate students to research mechanisms can offer valuable, authentic, and rewarding means to simultaneously advance their educational and professional development. Research mechanisms can open new pathways to improve comprehension of technical concepts through the application of the content in practical use cases, while simultaneously enhancing students' written and 
verbal communication skills [1]. Moreover, it develops problem-solving and critical thinking skills, as well as life-long learning while encouraging the undergraduate students to consider pursuing research through graduate education which can have positive influence on the long-term economic growth of themselves and the society [2,3].

In the current economy, there are a wide range of internships and paid work experiences available for the undergraduate students in various companies and corporations. Most of these work experiences provide short-term benefits to the students such as financial advantages and the joy of applying the technical skills they learned in the school to real-life application [2]. This may disproportionally advance and promulgate incomplete impressions that a one-time undergraduate education experience is sufficient to prepare them for their future career. However, on the other hand, there are not many comparable research opportunities available to expose them with the research-based career opportunities, whereas those which require a graduate-level depth of technical knowledge. A middle ground can be beneficial to show the students the excitement of a career in research via the mechanisms used without an extensive and more prolonged technical training of a typical Research Experience for Undergraduates (REU) activity.

With the continual advancement of technology, the need for a highly-skilled and well-educated work force is progressively increasing in both academia and industry. Thus, being exposed to research mechanisms during the delineation of engineering problems can assist undergraduate students to better understand options for sustaining career vitality. Those who are more aware are able to make more informed decisions regarding future career plans in both academia and industry. Moreover, connecting the course materials to the related state-of-the-art researches that are being conducted in the research community helps the students to comprehend the course fundamentals while getting familiar with the contemporary outcomes of the concepts they have learned. It also aids the course instructors to keep their course material up-to-date.

In addition, integrating research into undergraduate courses allow them to conduct more meaningful case studies with realistic parameters, which familiarize them with the types of problems they should deal with in their future career, while exercising the skills developed in the class. This approach also provides an opportunity for those students who are interested to go beyond the course basics and attain a more advance knowledge about the materials thought in the class. Thus, herein, we propose a hierarchical Learner Capstone Panel (LCP) approach, which can benefit students with different knowledge and interest levels and help them to improve their creativity and problem-solving skills.

\subsection{Essential Research Mechanisms for Undergraduate to Learn}

In the proposed approach, students are familiarized with various steps to develop a research paper for presenting it in a workshop, symposium, or conference. In particular, they are tasked to compose a capstone report in IEEE format, which connects the content of the course with the state-of-the-art advances in the field of computer architecture. During this process, students will learn the essential mechanisms required to develop and present a research paper, including how to:

1) Utilize research databases such as IEEEXplore and ACM Digital Library, as well as web search engines such as Google Scholar to find the highly-cited research papers recently published in their field of interest.

2) Follow a specific format defined by publishing organizations to create their capstone report.

3) Properly cite the articles they referred to within the capstone report. 
4) Participate in the process of double-blind peer review, and reviewing their classmates' capstone reports, as well as providing technical comments to improve the quality of the reports they have reviewed.

5) Experience a panel discussion as a speaker or spectator, and what are the methods to take advantage of their panel participation to learn new materials and connect with peers who investigated the same topic.

\subsection{Contribution and Outline of this Manuscript}

As identified above, one of the main challenges of current undergraduate studies is informing students about the many options that are available for them upon graduation from college. While there are many paid work experiences currently available for the undergraduate students, only a small fraction of undergraduates is conduct engineering research activities during their undergraduate studies. The typical undergraduate laboratory projects only include limited exposure to oral and written communication activities [3]. On the other hand, although there has been an increase in the Research Experience for Undergraduates (REU) programs funded by National Science Foundation (NSF) in recent years, these programs only provide opportunity to a limited number of students and it is not a general solution to address the issue.

Thus, in this paper, we identify an approach to integrate recent technical advances, introductory research methods, and professional conference activities within an undergraduate curriculum required Computer Organization course, which can be readily utilized by any other engineering courses. LCP provides viable solution to the challenge of exposing a wide range of undergraduate students to the engineering research problems. In particular, the main contributions of the paper are as follows:

- Relating the fundamentals concepts thought in the course to the recent well-known papers published in prestigious journals and conferences.

- Providing a detailed guide to prepare a conference-style document.

- Create a peer-review system using the online assessment tools.

- Provide a virtual collaboration environment and strategy through online collaboration tools such as eduPad [4] for panel discussion.

The remainder of the paper is organized as follows: a brief literature review of previous studies on undergraduate research is provided in Section 2. Section 3 discusses our proposed LCP approach in detail. Results and discussion of the LCP approach is provided in Section 4. Finally, Section 5 concludes this paper and discusses the summary of the proposed approach and future directions.

\subsection{Related Work}

Studies have shown that according to the student perception, immersing undergraduates in research mechanisms can have possible outcomes including but not limited to accumulation of new skills, understanding of new content, gaining knowledge in research methodology, ability to work independently, etc. [5, 6]. Recent studies among Science, Technology, Engineering, and Mathematics (STEM) students have shown that students involved with undergraduate research have significantly higher tendencies for pursuing a graduate degree [7]. Additionally, studies have discussed and shown the positive perception of students who have participated in undergraduate research programs [8, 9]. Although it is rather difficult to involve undergraduate students in every step of a research project, the undergraduate students will benefit from the research project by developing a set of skills that can be used in engineering problem-solving [10]. 
Studies have shown that undergraduate research experience can motivate students to pursue a graduate degree by providing them a meaningful experience to get familiar with graduate engineering education. Moreover, participating in undergraduate research can be beneficial and will result in a significant improvement in the quality of the education of undergraduate students, whether they want to pursue a professional degree or work for industry [2]. Furthermore, researchers have shown that undergraduate research programs can provide opportunities for active learning environments, which can result in significant improvements in student understanding and development of the engineering education [3]. These active learning opportunities can also benefit students who do not wish to continue their education towards a graduate degree [11]. Additionally, undergraduate research provides opportunities for students to get exposed to graduate-level education such as professional academic writing and research documentation, oral presentation, study of recent advances in the engineering field through study of the literature, and eventually composing scientific articles that meets high standards of conferences and journals [12].

Undergraduate research has been supported by federal funding programs such as National Science Foundation (NSF) Research Experience for Undergraduates (REU) program since 1987 [13]. According to the REU program description, undergraduate research experience is a useful mean to attract talented undergraduate students to careers in science and engineering. NSF REU program supports undergraduate research through REU supplements and REU sites, which both provide opportunities for undergraduate students who are U.S. citizens, U.S. nationals, or permanent residents of the United States, to gain valuable educational experiences by involving them in ongoing research projects funded by NSF or in research projects designed especially for undergraduate research experience purposes. Students who participate in REU programs participate interact and collaborate with faculty or graduate student mentors to achieve professional development goals sought by NSF [14]. At the University of Central Florida (UCF), research experience for undergraduate are supported by the Division of Teaching and Learning through programs such as Research and Mentoring Program (RAMP) [15] and Undergraduate Research Program [16] to provide research experience for those undergraduate students who are interested in pursuing a graduate degree. One of the main purposes of such programs is to encourage students from underrepresented groups and first generation/low income students to pursue graduate degrees $[15,16]$. According to the outcome of these programs, undergraduate researchers who participate in such programs: 1) are more likely to pursue a graduate degree, 2) demonstrate higher achievement and are more likely to stay in school, 3) have significantly better written and oral communication, critical thinking, technical skills, and information literacy $[15,16]$.

\subsection{Learner Capstone Panels Approach}

In this approach, the students select their preferred technical focus in computer systems design topics among a set of 5 to 7 technical focus topics such as reliability, circuit energy, memory read/write power consumption, etc. as identified by the course Instructor. Students are mentored on extending the course material from a topic list by the laboratory Graduate Teaching Assistants (GTAs) and the course Instructor. The students gain experience composing a scholarly article and produce a substantial paper that reflects a deep understanding of a topic having narrow breadth. Extra Credit (EC) is allotted to those learners who go beyond the baseline requirements and explore additional papers in order to provide a more comprehensive analysis. To receive full credit, the capstone report should include a complete comparison between the performance of their developed designs using various technologies, e.g. Complementary Metal Oxide Semiconductor (CMOS), spintronics, etc. that are proposed in each of the papers they have investigated. 


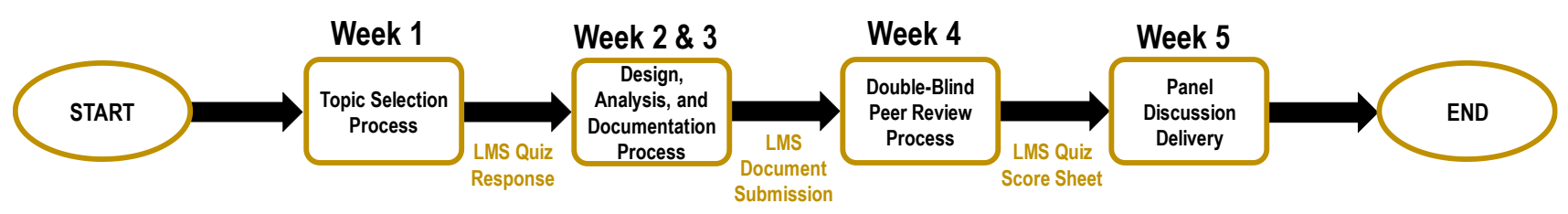

Figure 1: Overview of the proposed LCP approach.

Later, students will submit their capstone reports to the Learning Management System (LMS). The GTAs and the instructor of the course will rank the top ten scholarly reports exemplified all the requirements and prepared according to a rubric provided. Then, the students will have a chance to peerreview the top ten selected reports and vote for the top five. The authors of the top voted papers will be invited to participate in a panel discussion on the topic they have studied in their capstone reports. During the panel discussion, students will be engaged in scholarly debates in the relevant topics and will be asking questions from the panelists under the supervision and guidance of the Instructor of the course and the GTAs. Figure 1 shows the overall process of the proposed LCP approach.

\subsection{Topic Selection Process}

The topic selection process exposes the students to a variety of technical topics and requires them to study each topic to find their topics of interest. In the first week of LCP, GTA and faculty instructor will provide a set of 5 to 7 technically-specific topics that are related to the course contents covered in the lecture. The students are given one week to go over the topics provided and find their top 3 topics of interest. An online quiz is designed in the LMS to record students' responses to select their top 3 topic priorities. The LMS quiz will record the time and date of each response. Then, GTA extracts the LSM quiz report and sorts the responses with respect to date and time of submission. In order to keep the balance in the number of submissions for each topic, the number of students in each topic can be limited to a certain threshold. Thus, students who submitted earlier, will have a higher chance of being assigned to their first topic priority. Additionally, if the number of students in one topic reaches its threshold, the next student who has chosen this topic will be assigned to their next topic priority. The flow of the topic selection process is shown in Figure 2.

\subsection{Design, Analysis, and Documentation Process}

Herein, we have applied the proposed LCP approach within an undergraduate curriculum required Computer Organization course. In particular, GTAs have designed a project with the objective of enhancing students' comprehension of data transfer between processor and memory, as well as how to work with strings and arrays using MIPS assembly language programming. Students were are tasked to develop a program that finds how many times a word is repeated in a given statement by means of selected MIPS assembly language instructions, assembler directives, and system calls to handle the string manipulation tasks. The students were given a week to complete their project as shown in Figure

Week 1

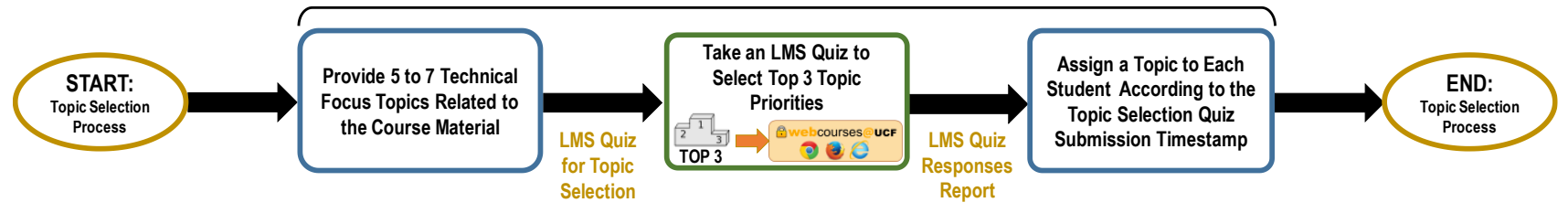

Figure 2: Overview of the Topic Selection Process. 

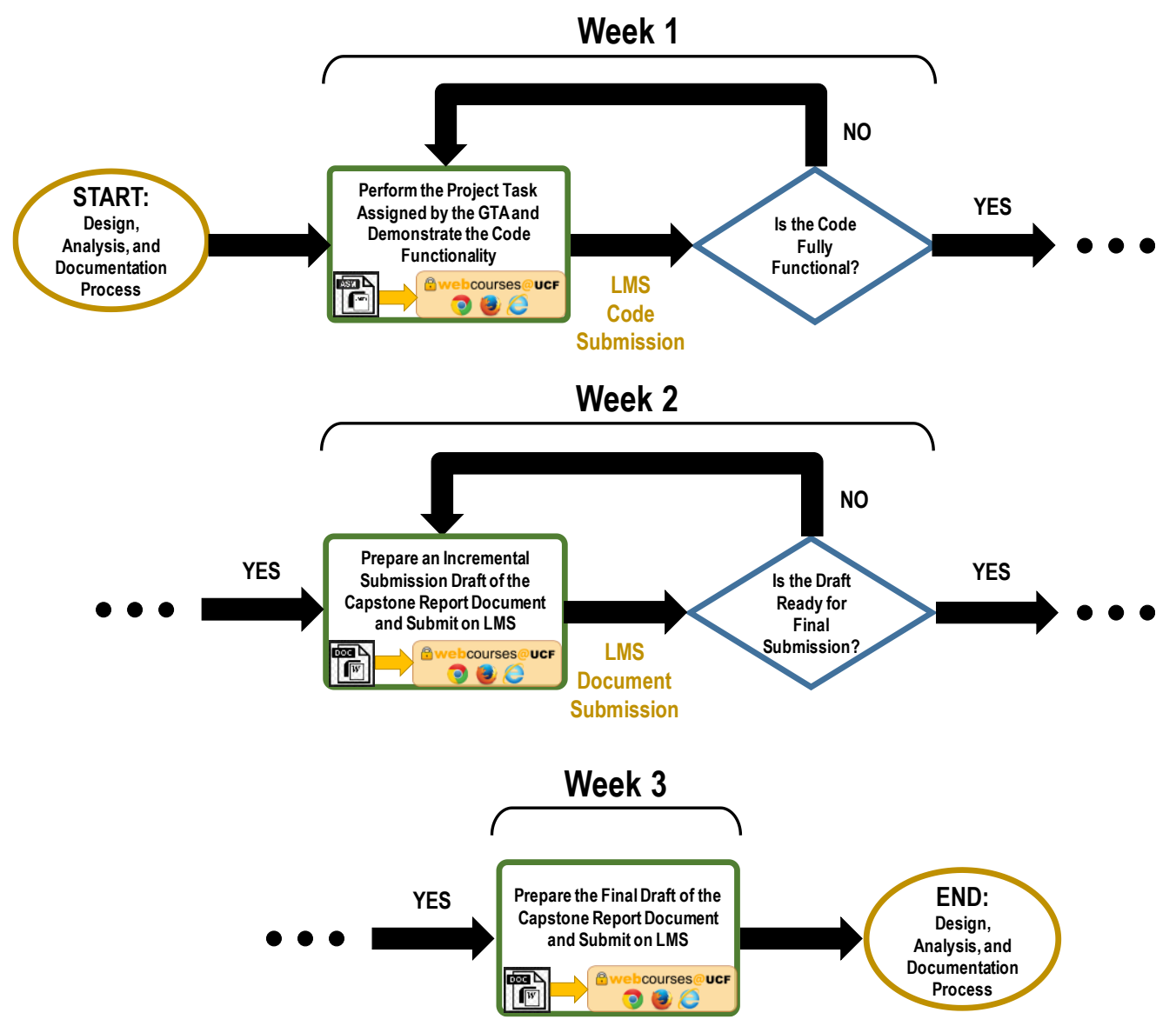

Figure 3: Overview of the Design, Analysis, and Documentation Process.

3. This part of the project included $30 \%$ of the entire project's grade, while the other $70 \%$ belongs to the capstone report that is described in the following.

To prepare the capstone report, students were asked to follow the double-column IEEE conference template. They should choose a technically-specific and unique title for they report, which identified some of the technical metrics they examined in their project. Moreover, they should provide an abstract with 100 to 200 words, which explains the objective of their report, as well as some of the main metrics they used in their analyses. The body of the capstone report includes four main sections: (1) Project Design: in this section, students should provide a detailed description about the assembly code that they developed, create a high-quality flowchart for their program, and provide at least three screen shots of the result of their MIPS code execution for different test inputs. (2) Technology Description: in this section, students should study four highly-cited references, selected by the GTAs, which are related to the topic they have chosen and provide a brief literature review. Moreover, they are tasked to use google scholar, IEEExplore, ACM Digital Library and/or related websites to add at least three other references to their summary. (3) Results and Discussion: in this section, students are tasked to calculate the energy consumption of their developed program using the energy per instruction values provided by the GTAs based on various device and circuit technologies. In particular, they should complete a comparison table based on the technologies provided by the GTAs. Also, they will be awarded 3 extra credit points for every row that they add to the comparison table using another related paper that they have found. This extra-credit strategy has shown to be particularly interesting to students considering pursuing research in the future. (4) Conclusion: finally, students are tasked to conclude their capstone report by providing a 

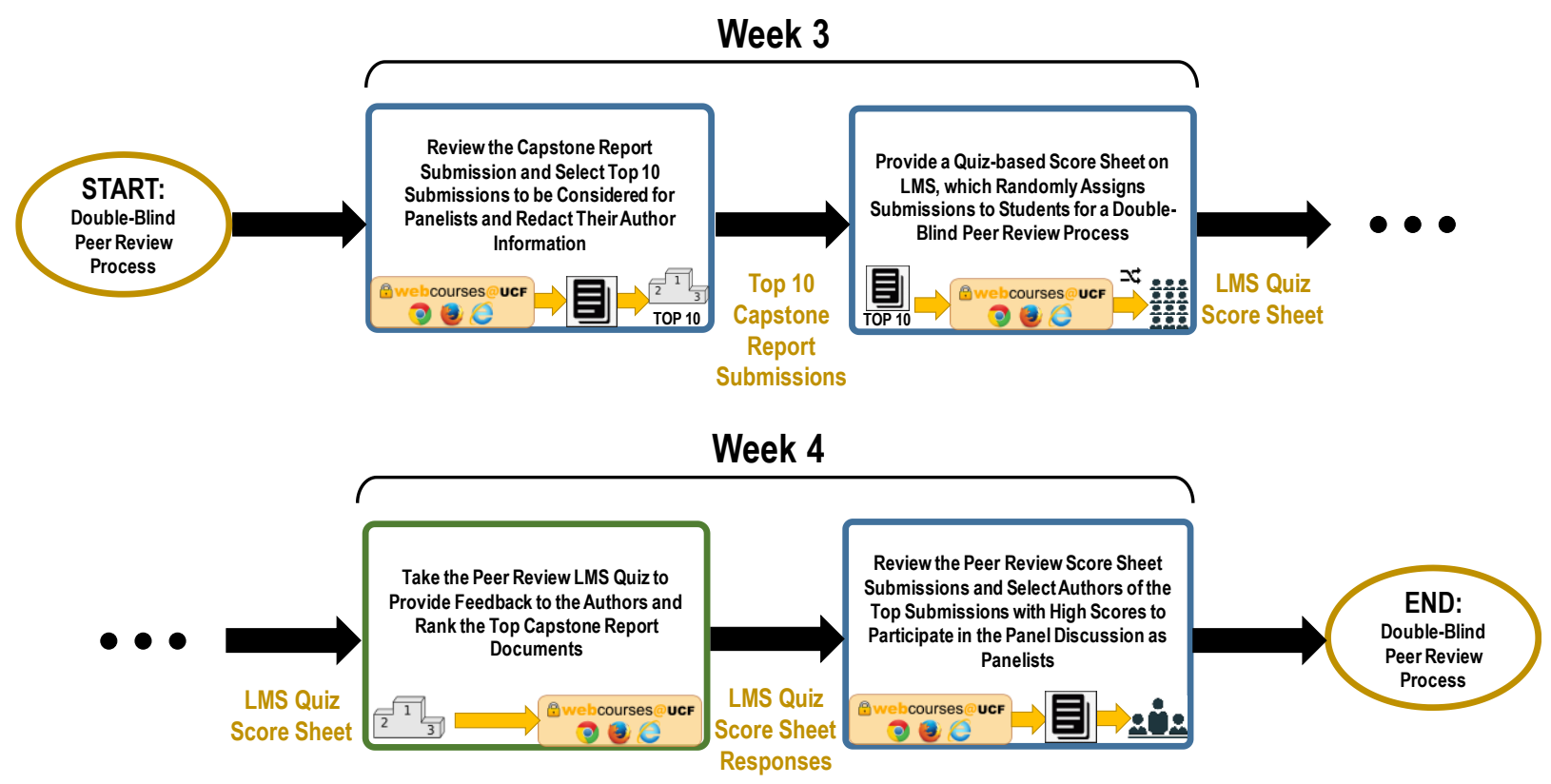

Figure 4: Overview of the Double-Blind Peer Review Process.

single paragraph regarding at least five technical points that they learned through completing the capstone report.

\subsection{Double-Blind Peer Review Process}

In order to implement a double-blind peer review process, we implement an LMS quiz. In order to increase the effectiveness and learning aspect of the double-blind peer review process, GTA and faculty instructor review the final capstone report submissions. Furthermore, GTA and faculty instructor select the top 10 high quality capstone paper submissions according to certain criteria, such as formatting of the capstone report, quality of writing, quality of figures, and quality of the analysis provided. After reviewing the capstone report submissions, the author information of the top 10 submissions is redacted for double-blind peer review process. In the peer review process, students provide a rating by responding to a questionnaire and their rating is used to rank the papers. According to the quantitative and qualitative responses to the peer review quiz, the ratings are used to select the panelists.

The peer review quiz is consisted of ten questions and asks about a variety of aspects such as technical quality and presentation of the topic covered, quality of formatting of text and figures, and whether the submission should be considered for panel discussion. An identification number is assigned to each redacted capstone report submission. First question of the peer review quiz is a question group that implements the random assignment of papers to students. This question group picks one text question from ten text questions, which each text question has a private link to a redacted paper from the top 10 capstone report submissions. This enables us to implement a double-blind review process since the author information of the capstone report submissions are redacted and the capstone report submissions are randomly assigned to the students. Thus, the authors won't know who reviews their submission and the reviewers won't know whose report they are reviewing. It is worth noting that the LMS implementation of the peer review process might not be fully double-blind due to the fact that there is a chance that authors of the top 10 capstone report submissions receive their own submission for peer review. However, this is an uncommon situation and we ask the students to declare conflict of interest in such cases, which then we will assign another submission to them for peer review. After the 
Week 5

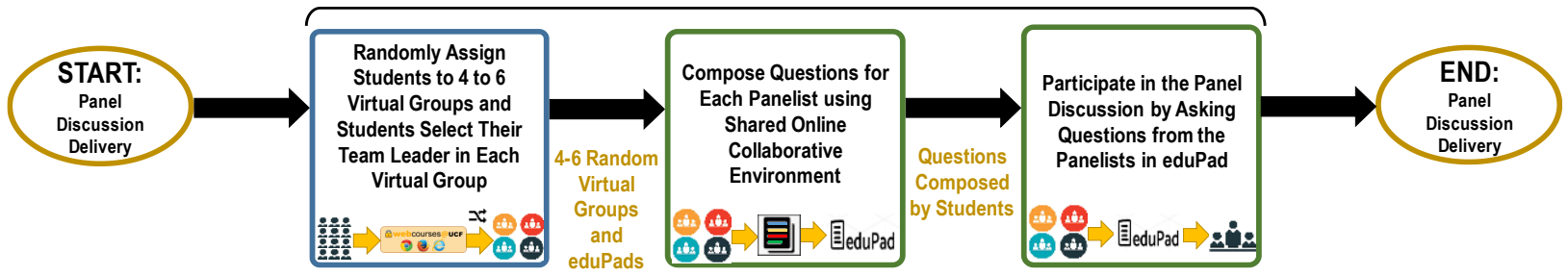

Figure 5: Overview of the Panel Discussion Delivery.

peer revision process, GTA exports the LMS quiz report, sorts the peer review results, and select the authors of the capstone reports with scores higher than a threshold, 4 out of 5 in our case-study, to be the panelists. The flow of the double-blind peer review process is shown in Figure 4.

\subsection{Panel Discussion Delivery}

For the panel discussion, GTAs use the tools existing in Canvas Webcourses to randomly distribute the students within the class to 4 to 6 virtual groups. Each group is provided with a unique link to the and online collaborative environment called eduPad [4], in which they can communicate throughout the panel session. EduPad is an online collaborative text editor that allows up to 15 users at a time to collaborate and enables anyone with the link to observe the collaboration in real-time [4]. In the first step, students in each group select their team leader for their virtual group in the eduPad document. Next, they will discuss within the group to compose related and appropriate questions to be asked from each panelist. Once the group agreed upon a particular question, the group leader will post the chosen question in a shared eduPad page which is projected onto a screen that can be seen by the entire class, GTAs, and instructor. Finally, GTAs and class instructor review all of the questions posted on the shared eduPad and pick specific questions to be asked from panelists, based on the importance and relevance of the question to various research topics investigated by the panelists and relationship of the question with course material. To

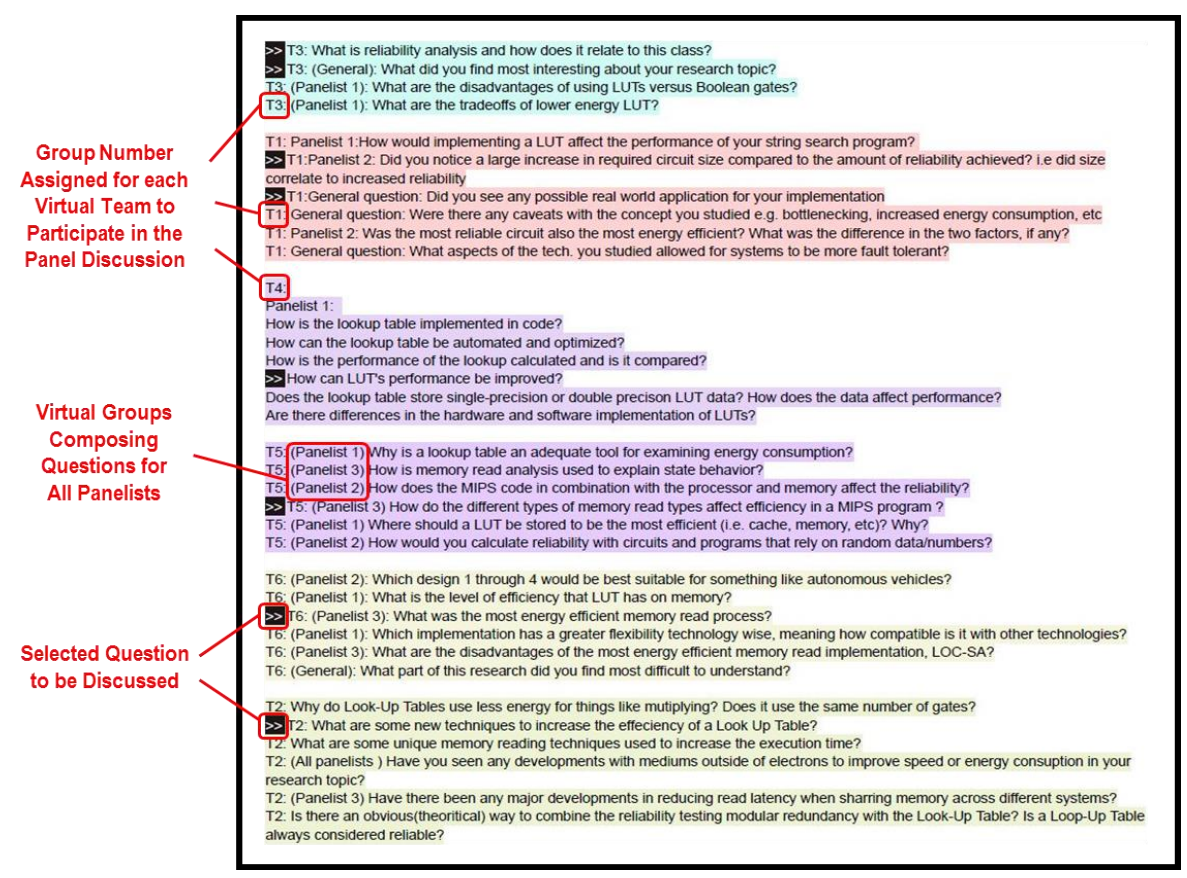

Figure 6: Screenshot the public shared eduPad for team leaders during panel discussion. Students in each virtual group come up with questions related to the panelists' topics of study for the capstone report and the team leader of each virtual group pastes most relevant questions in the shared public eduPad. 


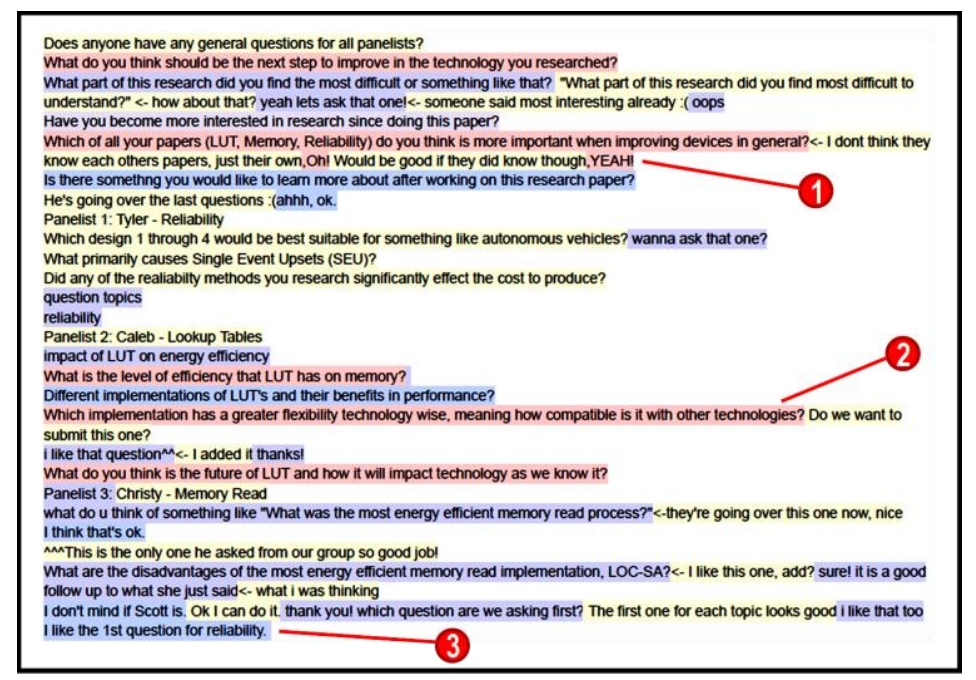

Figure 7: Screenshot of a sample private eduPad of a virtual group during panel discussion. Students in each virtual group were actively seeking to ask appropriate questions related to the panelists' topics of study for the capstone report and trying to maximize learning, as shown with numbers 1, 2 and 3.

encourage the students to actively participate in this process, the members of the virtual groups to which the selected questions belong to will attain EC points. Figure 5 exhibits the flow of the panel discussion delivery process. Moreover, a screenshot of the shared eduPad for a sample panel discussion in the Computer Organization course is provided in Figure 6.

\subsection{Results}

\subsection{Participation Statistics}

The population of the study included 134 undergraduate students who participated in the LCP approach in two sections of a computer engineering class. Participants in the LCP method were selected from a pool of students aged 10-47 (Mean=22), 86\% $(n=115)$ were male and $14 \%(n=19)$ were female. $40 \%(n=53)$ of the participants were White, $31 \%(n=42)$ Hispanic, $13 \%(n=17)$ Asian, 9\% $(n=12)$ African-American, and 7\% $(n=10)$ other ethnicities. Seniors accounted for the majority $79 \%(n=106)$ of the participants. The remainder were juniors $19 \%(n=26)$, sophomores $1 \%(n=1)$ or second degree students $1 \%(n=1)$. All students were either Electrical Engineering $(n=72)$ or Computer Engineering majors ( $n=62)$. Fifty-five capstone report submissions were made. Furthermore, In Section-01, there were 21 participants in the panel discussion from which 18 were active participants in the panel discussion. Additionally, in Section-02, there were 28 participants in the panel discussion, where 23 of them were active participants. In Figure 7 the participation and engagement of student in participating in the panel discussion can be observed in detail. Figure 7 depicts a screenshot sample eduPad of a virtual group consisted of six members, where each member is assigned a various color, during the panel discussion activity. It can be observed that only one member out of six members is not actively involved in the discussion, while other five team members are collaborating to ask questions from the panelists and engage in the panel discussion. According to the peer review process, four students in Section-01 and three students in Section-02 were selected to participate in the panel discussion as panelists. During the panel discussion, 40 questions were composed in the shared eduPad of Section-01 and 34 questions were composed in the shared eduPad of Section-02, which demonstrates that the students were actively participating in the panel discussion.

\subsection{Student Perception Survey Results}




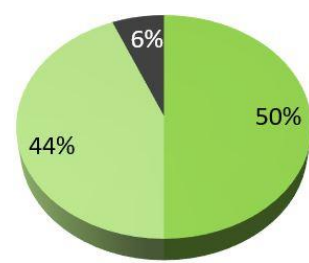

(a)

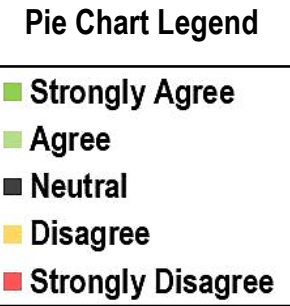

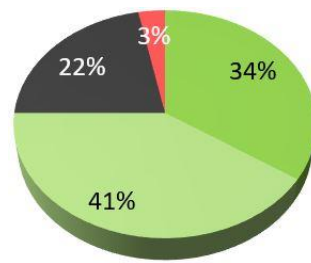

(b)

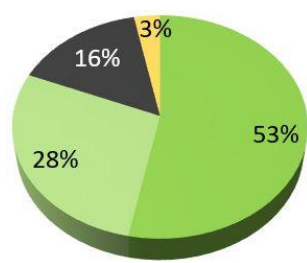

(c)

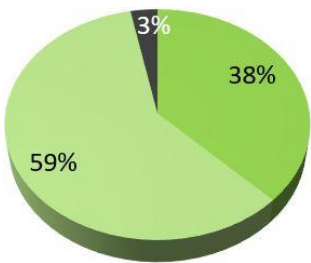

(d)

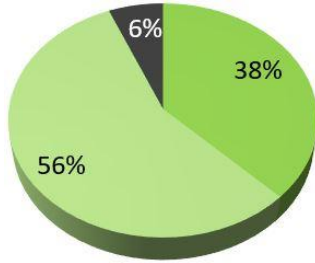

(e)

(a) Working on a Capstone Report helped me to better understand the process of creating a research paper

(b) The Capstone Report motivated me to explore beyond the course materials

(c) Attending the panel discussions increased my understanding of research topics related to the course materials

(d) I have understood how to prepare a technical report in IEEE Format by composing a Capstone Report

(e) I learned how to compare and contrast technical attributes of various related works in a specific technical topic by doing the Capstone Report

Figure 8: Student perception survey results $(n=34)$.

In order to evaluate the effectiveness of the proposed LCP approach, an anonymous IRB-approved online survey was released at the end of the semester to gain insight regarding student perception. Thirty-four surveys were received from students. The survey consisted of twelve Likert-scale (1="Strongly Disagree"; 5="Strongly Agree") items designed to measure students' perceptions of the LCP method and the usefulness of the LCP method.

The results of the survey responses are shown in Figure 8. Results have shown that $94 \%$ of the survey responders strongly agreed or agreed that working on a capstone report helped them better understand the process of creating a research paper. Additionally, 75\% of the responders strongly agreed or agreed that the LCP method motivated them to explore beyond the course materials. Moreover, $81 \%$ of the survey participants strongly agreed or agreed that attending the panel discussions increased their understanding of research topics related to the course materials. Furthermore, $97 \%$ of responders strongly agreed or agreed that they have understood how to prepare a technical report in IEEE format by composing a capstone report. Finally, $94 \%$ of the responders strongly agreed or agreed that they have learned how to compare and contrast technical attributes of various related works in a specific technical topic by doing the capstone report.

\subsection{Conclusion}

This paper proposes a novel and transportable approach to integrating research methods, professional conference activities, and technical current topics at University of Central Florida (UCF), integrated within a required undergraduate Computer Engineering course. The proposed approach, called Learner Capstone Panel (LCP), motivates learners to become immersed in mechanisms of creating technical reports that connect the content of the course to the state-of-the-art advances in the field. LCP assists undergraduate students become immersed in mechanisms associated with technical research while becoming cognizant of options that they could pursue during graduate studies in topics of their interest that also refresh content within the course. Our results based on an IRB-approved survey indicate that on average more than $88 \%$ of the participants strongly agreed or agreed that the LCP approach increased their understanding of research topics related to the course materials, helped them better understand the process of creating a research paper, and motivated them to explore beyond the course materials. Overall, the authors found that LCP approach can offer an effective mechanism to advances students' professional development via simulated participation in a professional technical conference panel environment, which is typical unattainable for undergraduate students. 


\section{References}

[1] D. A. Willis, P. S. Krueger, and A. Kendrick, "The Influence of a Research Experiences for Undergraduates Program on Student Perceptions and Desire to Attend Graduate School," Journal of STEM Education: Innovations and Research, vol. 14, no .2, pp. 21, 2013.

[2] W. D. Jemison, W. A. Hornfeck, and J. P. Schaffer, "The Role of Undergraduate Research in Engineering Education," In Proceedings of the 2001 ASEE Annual Conference, Albuquerque, NM, 2001.

[3] N. Dukhan, and M. Jenkins, "Undergraduate Research as a Motivation for Attending Graduate School,” In Proceedings of the 2001 ASEE Annual Conference, Honolulu, HI, June 2007.

[4] EduPad Online Collaborative Text Editor, Available at: https://www.edupad.ch/.

[5] D. Lopatto, "Undergraduate research Experiences Support Science Career Decisions and Active Learning," CBE - Life Sciences Education, vol. 6, no. 4, pp. 297-306, 2017.

[6] E. Seymour, A. Hunter, S. L. Laursen, and T. Deantoni, "Establishing the Benefits of Research Experiences for Undergraduates in the Sciences: First Findings from a Three-Year Study," Science Education, vol. 88, no. 4, pp. 493-534, 2004.

[7] M. K. Eagan, S. Hurtado, M. J. Chang, G. A. Garcia, F. A. Herrera, and J. C. Garibay, "Making a Difference in Science Education: The Impact of Undergraduate Research Programs," American Education Research Journal, vol. 50, no. 4, pp. 683-713, 2013.

[8] A. L. Zydney, J. S. Bennett, A. Shahid, and K. W. Bauer, "Impact of Undergraduate Research Experience in Engineering," Journal of Engineering Education, vol. 91, no. 2, pp. 151-157, 2002.

[9] M. K. Boyd, and J. L. Wesemann, "Broadening participation in undergraduate research: fostering excellence and enhancing the impact," Washington, DC: Council on Undergraduate Research, 2009.

[10] S. Kaul, C. Ferguson, P. Yanik, and Y. Yan, "Importance of undergraduate research: efficacy and student perceptions," In Proceedings of the American Society for Engineering Education Annual Conference and Exposition, New Orleans, LA, 2016.

[11] L. J. Shuman, M. Besterfield-Sacre, and J. McGoury, "The ABET "Professional Skills"- Can They Be Taught? Can They Be Assessed?," Journal of Engineering Education, vol. 94, no. 1, pp. 41-55, January 2005.

[12] M. C. Partti, "Communication as Professional Practice: Designing Assignments to Develop Engineering Professionals," ASEE Southeast Section Conference, The University of Tennessee at Chattanooga, April 3 - 5, 2005.

[13] C. A. Yauch, "The impact of undergraduate research experiences on graduate school pursuit by industrial engineers," 2007 37th Annual Frontiers In Education Conference - Global Engineering: Knowledge Without Borders, Opportunities Without Passports, Milwaukee, WI, pp. S4B-17-S4B-21, 2007.

[14] National Science Foundation (NSF) Research Experience for Undergraduates (REU) Documentation, Available at: https://www.nsf.gov/pubs/2013/nsf13542/nsf13542.pdf.

[15] UCF Research and Mentoring Program (RAMP), Available at:

https://aap.ucf.edu/programs/ramp/.

[16] Undergraduate Research, Division of Teaching and Learning at the University of Central Florida (UCF), Available at: https://our.ucf.edu/. 